\title{
THE COLLEGE'S EVIDENCE TO THE THE PRISON SERVICES INQUIRY*
}

In giving evidence to this Inquiry the College is concerned with the future of the Prison Medical Service, and particularly the pressures resulting from the large number of mentally disordered persons in prisons; the relationship of the Prison Medical Service to psychiatric and other health services in the community; recruitment into the Prison Medical Service; the future development of forensic psychiatry in relation to the Prison Medical Services, and related matters.

\section{Background}

The influence of John Howard in the last quarter of the 18th century led to a compulsory requirement for prisons to have a surgeon appointed to care for the sick. The establishment of the Prison Commissioners in 1877 was followed by the appointment of a fulltime Medical Inspector and the beginning of an organized full-time medical service. In 1906 the Home Office sent a circular to magistrates' courts drawing attention to the services of medical officers in providing 'state of mind' reports upon prisoners remanded in custody. However, it was not until 1919 that a full-time medical officer was appointed (to Birmingham) with the remit of investigating the mental state of those on remand and reporting to the court whether treatment or punishment was appropriate.

The Committee on Persistent Offenders in 1932 recommended the appointment of 'medical psychologists' to treat selected sentenced individuals, and $\mathrm{Dr}$ W. H. Hubert was appointed the first visiting psychotherapist to Wormwood Scrubs Prison. Following the East-Hubert Report in 1939 further psychotherapists were appointed; but, as the demand for psychiatric reports to courts increased, prison doctors had to regard psychiatric work as an increasingly important aspect of their duties, since the majority of individuals requiring reports were remanded in custody.

When the National Health Service was introduced in 1948 the Prison Medical Service continued as a separate, autonomous service, its full-time medical officers being civil servants. It is probable that there has always been a sizeable number of mentally abnormal individuals held in prisons, recognized as such to a greater or lesser extent; but the current problems probably date from the introduction of the Mental Health Acts, the emphasis on an open-door policy in psychiatric hospitals, the move from mental hospital to district general hospital psychiatric unit, the necessary increased stringency of application for admission policies at the Special Hospitals and a loss of community facilities. As a result of this and the hardening of attitudes on the part of Health Service psychiatrists, there has been a large accumulation of mentally abnormal individuals in prisons, and this has contributed to the rapid growth of the prison population.

While prison doctors had a responsibility for providing psychiatric reports and psychiatric treatment in prison hospitals there was difficulty in attracting sufficient recruits of suitable calibre and qualification who would be able to make a valuable contribution to the diagnostic work and to the other duties of the Prison Medical Service.

In 1964 the Institute of Psychiatry, the National Association for Mental Health, the Royal College of Physicians and the R.M.P.A. all recommended complete integration of the Prison Medical Service with the National Health Service. The B.M.A. and the Institution of Professional Civil Servants gave an opposite view, and the Gwynn Committee, which was apparently evenly divided on the matter, decided against recommending integration. Even so, they made it clear that their decision should be seen as temporary. Compromise recommendations included the proposal for the appointment of forensic psychiatrists jointly between the NHS and the Home Office and the regionalization of the Prison Medical Service. In evidence the Lord Chief Justice expressed the hope that all psychiatric reporting might in future be carried out by the jointly appointed psychiatrists and their colleagues.

In its evidence to the (Butler) Committee on Mentally Abnormal Offenders the College recommended: 'there should be a much closer integration between the Prison Medical Service and the National Health Service in the clinical and management fields, with facilities for the interchange of staff without detriment to career prospects, conditions of service and pension rights. This should apply to doctors, nurses, clinical psychologists and other staff.' Meanwhile there was a need for an expansion of joint appointments at consultant and other levels with the development of adequate training facilities. Links with the universities and other academic centres were also important.

Both the National Association for Mental Health

${ }^{*}$ Prepared by the following Special Committee: Chairman, Professor K. Rawnsley; Members: Drs R. Bluglass, P. Bowden, B. D. Cooper, W. McConnell, P. G. McGrath, P. Whatmore. The document has been approved by the Executive and Finance Committee and endorsed by Council, but is slightly abbreviated for publication. 
and the Joint Consultant Forensic Psychiatrists recommended amalgamation of the two services. The Butler Report (October 1975) said that a few joint appointees had brought about significant improvements in the services in their locality, but in the majority of cases the essential linkage between the National Health Service and the Prison Medical Service had not taken place. 'This attributed largely to the continued isolation of the Prison Medical Service and in part to a lack of understanding of the potential of the joint appointments'. The Report expressed the belief that the establishment of forensic psychiatric services should achieve the desired objectives more easily than the mere appointment of individual consultants with virtually no supporting organization who could only depend upon the willingness of the Prison Medical Service to accept them as full members of the team.

The Butler Committee refrained from recommending integration, in part because it was doubtful if such a recommendation was within the Committee's terms of reference, but also because they were persuaded that the recommendations on the establishment of effective forensic psychiatric services would, if implemented, make a significant contribution towards improving the handling and disposal of mentally disordered offenders.

\section{Recent Developments}

The failure of the concept of joint appointments between NHS and Prison Medical Service was referred by the Royal College of Psychiatrists to a Working Party, which identified factors considered responsible for this situation:

1. National Health Service consultants and Prison Medical Officers have different career structures, responsibilities and contractual obligations. It was difficult to envisage how, in the present circumstances, a NHS consultant could have a role other than to provide a consultative link with NHS resources.

2. Joint appointments have not been tailored to suit local needs either in terms of resources or in relation to the particular experience of individuals involved.

3. The joint consultants have limited facilities outside prisons and are unable to respond as they would wish to the needs of all the inmates requiring transfer to Health Service facilities.

In consequence, in March 1978, Council of the College made a recommendation, which was recognized as to some extent retrograde, that consultants should no longer be jointly appointed between the Home Office and the National Health Service.
It is necessary to ask whether the present structure and function of the Prison Medical Service is the one best suited to delivering the highest possible standard of health care. Although much of the blame for the present crisis in the prisons can be attributed to National Health Service policies, other forces have been at work. It has already been argued that the Prison Medical Service-like other low-prestige medical services-has experienced difficulty in recruiting suitable candidates and the hoped-for crossfertilization with the NHS has not occurred.

Several factors should be recognized if prisoners are to be provided with the highest possible level of health care: that any separate system for a minority group tends to be a poor standard system; that prisons highlight the doctors' dilemma in bringing into sharp focus situations where there might be conflict between the priscners' interest and those of society; that the widely criticized Official Secrets Acts (1911 and 1920) can have an effect on clinical independence; that prisoners have a high morbidity in terms of physical and mental disorder and that suspected mental disorder is a criterion for imprisonment where individuals are remanded for medical reports; that the forces of the total institution powerfully influence staff and inmates; that Prison Medical Officers are in a unique position of diagnosing need and rejecting or selecting for individual services, thereby applying the strictures or benefits of society. It was in recognition of these particular influences that the United Nations Congress on Prevention of Crime and Treatment of Offenders adopted 'Standard Minimum Rules for the Treatment of Prisoners' (1958), in which is stated: 'The medical services should be organized in close relation to the general health administration of the community or nation'.

The majority of the growing number of forensic psychiatrists have appointments in the National Health Service where the official DHSS policy is directed towards establishing regional secure units. There is an increasing concern for the 'rights' of prisoners and a call to assess and treat mentally abnormal offenders as far as possible in the community. The new Bail Act has encouraged these developments, most of which were not evident 15 years ago.

As stated earlier, the problems faced by prisons and the increasing pressure upon them is, as far as abnormal offenders are concerned, related to the failure of the National Health Service to develop services for these offenders in the community.

The most relevant recent report in relation to these matters is the 15th Report from the Expenditure Committee of the House of Commons (Session 1977 . 
1978, 'The Reduction of Pressure on the Prison System', Volume 1, Report, July 1978). In Chapter 3 the Sub-Committee examined various methods by which a reduction of pressures on the prison system might be achieved. They included a reduction in the use of imprisonment for certain categories of offenders: mentally disordered offenders; drunks, alcoholics and persons with a drink problem; inadequate offenders. Chapter 4 is concerned with categories of prisoners which need to be reduced in number. The report recommends "The DHSS should accept more responsibility in seeking solutions than it appears to have done up to now, and actively seek to inform and persuade both medical and nursing staff and the general public of the nature and dimension of the problem and of the serious consequences which may flow from neglecting to find solutions. The DHSS should pay for the accommodation in prisons of mentally disordered offenders until such time as they can be transferred to mental hospitals'. The report goes on to say that even when there is adequate provision for difficult and dangerous offenders in regional secure units, there will remain many who will still have to be contained in prisons. The report states that while therefore 'we recommend that the provision of regional secure units should be treated as a matter of greater urgency, we also recommend that the Home Office should:

1. recognize the need for its Prison Department to expand its own psychiatric facilities;

2. consider the establishment of more special wings such as ' $C$ ' wing at Parkhurst Prison;

3. consider the appointment of a Director of Psychiatric Services, to work in partnership with the Director of Prison Medical Services, but charged specifically with developing the psychiatric side of the Prison Medical Service in liaison with the DHSS and Regional Health Authorities;

4. take steps to increase the attractiveness of the Service to psychiatrists by payment of a special premium for the arduous and responsible nature of their work.'

The recommendation for the appointment of a Director of Psychiatric Services is unlikely to solve the problems outlined above. The Prison Medical Service would continue to have difficulty attracting people of the right calibre, and by developing the prison psychiatric services as a separate entity the present problems would continue.

Deficiencies in Existing Prison Medical Services

Since prisoners are already disadvantaged, the facilities available for their treatment should be at least equal to those in the community. However, the high morbidity of those imprisoned, which can be compounded by disabilities induced by the process of imprisonment itself, is met by a general tendency to reject and scapegoat prisoners so that the services provided for them are often minimal.

Difficulties in providing health care reflect the inadequacies of other amenities for prisoners. Overcrowding is a most serious problem and those sentencing must seek alternatives to imprisonment. This would include the provision of better resources within the NHS, but this is unlikely to be realized if developments are in financial competition with other services.

The Prison Medical Service is isolated within the medical profession, and doctors in prisons sometime bear the brunt of the hardening of attitudes which results from criticism of prison officers and administrative staff. The recruitment of suitable Medical Officers remains inadequate and both fulltime and part-time staff are about one-fifth below complement. Although some Medical Officers have a diploma in psychiatry, there is a tendency for promotion to be weighted in favour of administrative posts so that the best qualified Medical Officers are not engaged in clinical work. Unfortunately many of the Medical Officers with psychiatric qualifications are expected to retire in the next few years and it is very unlikely that they will be replaced by colleagues with similar experience.

The working environment for Medical Officers is poor both in terms of physical amenities and back-up services (e.g. secretarial), and their clinical practice is restricted largely to males of one socio-economic group. Medical Officers are unable to follow up their prisoner-patients into the community, or be involved in work with families or offenders who receive sentences other than with imprisonment. Ethical problems are raised by the demands of non-medical staff but the isolated Medical Officer tends to meet these by denying that there is a conflict.

While psychiatric hospitals and units in the National Health Service are inspected and posts approved, for instance by the Royal College of Psychiatrists, the Joint Committee on Higher Psychiatric Training and the Health Advisory Service, psychiatric services in prisons are not subjected to the same degree of scrutiny. The Prison Medical Officer has not been able to broaden his role, thereby reflecting the changing attitudes and practices of psychiatry, as was recommended by the Streatfield Committee (1961), but continues to have a limited and restricted function.

\section{Recommendations}

1. For mentally disordered offenders the alternative to imprisonment is the development of facilities in the 
NHS. These require additional funding which must be earmarked specifically for the purpose;

2. Medical services to prisoners should be provided wholly by the NHS, and several categories of medical practitioners can be identified:

Firstly, general practitioners who would be responsible for the provision of primary health care to prisoners, whether remanded or sentenced, including basic psychiatric services. General practitioners would be contracted to provide a full range of services to prisoners in the same way as they serve patients in the community. They would also be responsible for managing in-patients in existing prison hospitals.

Secondly, community physicians would be employed by Districts to provide public health requirements of prisons. Their duties would include the present statutory functions of Prison Medical Offcers which are not concerned with primary health care.

Thirdly, it would be necessary to provide an administrative grade which would co-ordinate the medical services provided by general practitioners, community physicians and specialists. The administrative doctor might work mainly in one prison if the medical services were complex, for example in a large remand prison, but would normally be responsible to several penal establishments.

Fourthly, specialist services would be provided by forensic psychiatrists, and the specialty would be developed to give a service in both prisons and the community. Where forensic psychiatrists were not available, general psychiatrists with a special interest would provide the necessary manpower, but continuity of care is essential here too.

3. The provision of a comprehensive psychiatric service to prisons, including the furnishing of psychiatric reports at the request of the courts, should be the responsibility of the NHS and be part of the contractual obligations of forensic psychiatrists.

4. Doctors would be limited to working no more than seven sessions weekly in penal establishments so that they can be adequately exposed to the practice of medicine in the community.

5. Existing Prison Medical Officers would be assimilated into NHS grades with complete protection of emoluments.

6. Better facilities would be required in prisons for both general practice and specialist care. Resources should at least be equal to those available in the community. Most importantly it would be necessary to develop those professional services which normally exist alongside psychiatry, for example occupational therapy, social work, nursing and psychology.

7. Nurses should be recruited from prison officers who would receive the appropriate training whilst in service. All training would be comparable to that available in the NHS and subject to the same monitoring. Penal establishments would be used by training psychiatrists in the same way as NHS facilities.

8. Careful consideration should be given to relationships between NHS doctors and prison staff. Responsibilities on the interface between these groups must be clear, and the definition of roles should be considered by a working party comprising interested professional parties.

9. The DHSS should have a section concerned with prison services. Because of the difficulty in obtaining informed consent, all clinical research in prisons should be subject to the scrutiny of the Forensic Psychiatry Research Liaison Group at the DHSS.

10. To facilitate the development of a range of treatments in penal establishments and to emphasise their similarity with those available outside, the provisions of the Mental Health Acts should be extended to prisons. 